\title{
Women's place-making through craft in post-earthquake Christchurch
}

\author{
Jane Maidment ${ }^{1}$, Raewyn Tudor ${ }^{1}$, Ada Campbell ${ }^{2}$ and Karen Whittaker ${ }^{3}$
}

\begin{abstract}
INTRODUCTION: There is little research on the role of creative arts and craft in disaster recovery. This article reports findings about the emergent role of crafting from research conducted after the 2010-2011 series of earthquakes in Christchurch and surrounding districts in Aotearoa New Zealand. In particular, the article focuses on the significance and differing interpretations of the notion of place expressed by participants through their craftwork, in this case led by women and mediated by the post-earthquake geographic and temporal context.

METHOD: This qualitative research included nine individual interviews and five focus group interviews with crafters from Christchurch and surrounding districts. There were 35 participants in total, 33 were women. Applied thematic analysis was used to code the data and identify themes. These themes included connection to place, the symbolism of craft, the healing experience of craft groups and places for women. The notion of place was evident across all three themes.
\end{abstract}

FINDINGS: The findings from the research demonstrate differing ways in which the significance of place was reflected in the craftwork. Participants interpreted the concept of place in descriptive, symbolic, and therapeutic ways.

IMPLICATIONS: More understanding about the way creative endeavours like crafting can be used to help ameliorate the impact of natural disasters is needed. Social work practitioners are encouraged to explore place-based wellbeing during their work with service users and to include aspects of artistry, craft and creativity.

KEYWORDS: place; women; disaster; social work; craft; groups

The impact of the 2010 and 2011

Christchurch earthquakes was felt keenly through damaged housing and lost or relocated employment; fracturing the social wellbeing of people, dislocating longestablished community connections through forced moves; layered by the loss of cultural heritage such as well-known landmarks and destinations of personal significance such as churches and schools. In this article we document research undertaken about the creative and generative responses to the disaster offered through engagement with crafting.
Within the disaster literature, women are often portrayed as vulnerable, needing assistance and awaiting rescue from men (Enarson, 2016; Enarson \& Morrow, 1998; Heijmans, 2001), and these depictions were frequently reinforced by media portrayal of the Christchurch earthquake rescue and response that highlighted the efforts of male personnel (Earthquake Commission [EQC], 2014). Yet in the aftermath of the earthquakes, women were at the forefront in providing practical support. These efforts included the provision of food and transport to family, friends and the wider community; coordination of relief
${ }^{1}$ University of Canterbury

2 Ara Institute of Canterbury ${ }^{3}$ Anglican Care Community Development
AOTEAROA

NEW ZEALAND SOCIAL WORK 31(1), 17-30.

CORRESPONDENCE TO: Jane Maidment jane.maidment@canterbury.ac.nz 
efforts, advocating and generating recovery initiatives such as "Greening the rubble" a project aimed at enhancing demolition sites with horticultural enterprise. Women's efforts post-earthquakes remained largely invisible to the media but focused on strengthening family connectedness, offering direct services and looking for ways to engage with, and restore, local communities (Gordon, 2013). The crafting initiatives we write about in this article are part of community healing practices led by women where social connectedness was facilitated through the coming together and creation of artefacts by hand.

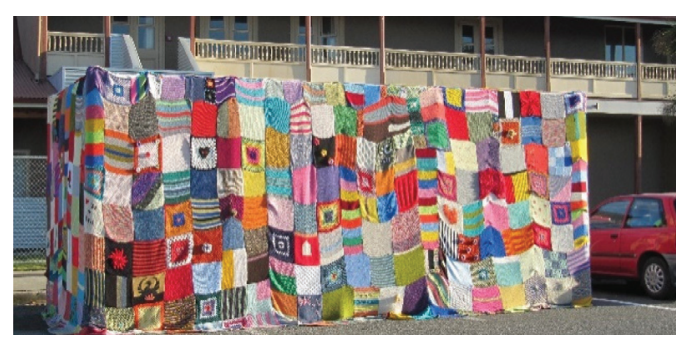

Authors' own. Patchwork container cover.

In this article we reflect upon the handcrafting that occurred in postearthquake Christchurch and Lyttelton with specific reference to the notion of place. Projects such as the Lyttelton Hearts, in which a group of women crafters made and attached large fabric hearts to barrier fencing around damaged buildings reminded passers-by that these were loved and valued places, conveying a sense of hope and renewal. Throughout the city, large steel containers were used to protect the roads from unstable building facades and rockfall. The roads leading into the suburb of Sumner were lined with containers with one becoming the focus for a group of women crafters who covered it in crocheted and knitted squares. Contributions to the patchwork cover came from all over the world as people sought to make a connection and contribution to the Canterbury region in the weeks and months following the major earthquakes. These projects demonstrate ways in which women crafters sought to shape the environment in places where the physical landscape had dramatically changed. As crafters, researchers and practitioners in the helping professions we draw attention to the contribution these crafting activities made for offering moments of contemplative reflection, inspiration and meaning-making in the midst of crisis and physical ruin wrought by the initial earthquakes and thousands of aftershocks. In presenting these moments of creativity and hope our aim is to offer social workers opportunities to recognise and explore placebased wellbeing through creative mediums within their community-based disaster recovery work.

Debates about defining what constitutes crafting, particularly in relationship with the arts are longstanding (Niedderer \& Townsend, 2014). For the purposes of our research craft is understood to be:

[B]ound to the hand, to the process of making. Beginning with the imagination and laying out the parameters of design, it is the skill of the hand that results in a thing well made, a thing that rightfully can claim the title of "craft". (Fariello, 2011, p. 23)

Furthermore:

A craft product is not the end result of the process; it may include a complex variety of values and emotions as well as shaping the identity of the maker. (Pöllänen, 2013, p. 219)

In this study, the craft objects created by the women participants were produced through embroidery, knitting, hand-stitching and crochet.

\section{Review of the literature}

The most commonly reported psychological impacts for those affected by disasters are anxiety, depression, and posttraumatic stress disorder (PTSD), resulting in increased relationship difficulties and usage of mental health services (Aiena, Buchanan, Smith, \& Schulenberg, 2016). Certainly, in the 
years subsequent to the earthquakes in Christchurch, adverse mental health impacts have been noted for adults (Spittlehouse, Joyce, Vierck, Schluter, \& Pearson, 2014), accompanied by a $93 \%$ increase in demand for mental health services for children (Kai Tiaki, 2018). Of particular interest for this research into crafting, is the relationship found between the capacity for meaningmaking with increased resilience postdisaster (Aiena et al., 2016).

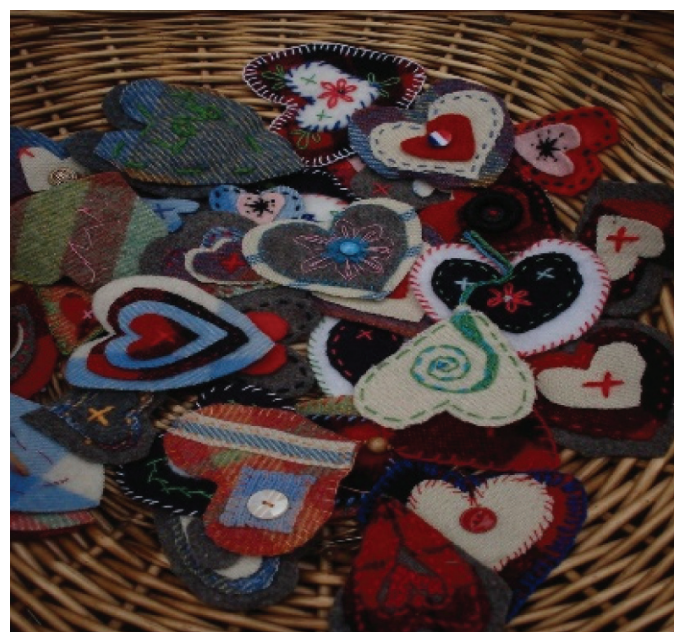

Bettina Evans. Handstitched hearts.

In a city and region heavily impacted by the devastation of the earthquakes, creative and generative activity quickly emerged through a range of community-led initiatives (Beatley, 2014). Within the disaster context, the notion of communal coping as distinct from social support views problems as shared concerns where people together take responsibility for developing action or an intervention (Richardson \& Maninger, 2016). The crafting groups and creative community initiatives we engaged with post-earthquake resonated with this conceptualisation of communal coping where the act of sewing a heart and giving it to a stranger on the street, or carefully choosing a subject to embroider in a collective work was integral to fostering both personal and collective coping and wellbeing.

The restorative capacity of crafting to help women cope with significant stressors and major life transitions has been identified in earlier research (Pöllänen, 2013; Riley, Corkhill, \& Morris, 2013). Multiple studies note how engaging in crafting activity helps to ameliorate and manage the effects of living with mental health conditions and physical illness resulting in chronic pain (Collier, Wayment, \& Birkett, 2016; Cour, Josephsson, \& Luborsky, 2007); come to terms with bereavement (Kohut, 2011); generate a sense of empowerment (Maidment \& Macfarlane, 2011); with crafting groups providing places of relational safety, support, learning and inspiration (Schofield-Tomschin \& Littrell, 2001; Horghagen, Fostvedt, \& Alsaker, 2014). It is at this point that research on disaster recovery and that related to crafting intersect with both spheres of research signalling ways for fostering wellbeing.

\section{Coping}

There is a growing body of research noting the relationship between engagement with the production of visual arts and growing resilience (Macpherson, Hart, \& Heaver, 2016). There is however, less empirical evidence about how the practice of crafting contributes to strengthening individual and community coping capacity. While the authors above note the positive effects of communal coping as part of disaster response, it is evident that women derive significant coping capacity from engaging in crafting where, particularly in times of significant stress, the importance of a meaningful leisure activity is most evident (Pöllänen, 2015). Specifically, leisure activity provides space for "distraction, a respite and escape from daily stress" where people are able to exercise a sense of agency and control (Denovan \& Macaskill, 2017, p. 452). Meeting in groups to craft has been found to generate a sense of stability and routine while promoting participation, inclusion, and cooperation (Horghagen et al., 2014). These factors crucially contribute to garnering a measure of control (Pöllänen, 2015), particularly significant in a milieu where many aspects of daily living are subject to uncertainty as is 
the case in the aftermath of a natural disaster. The beneficial role of crafting as a means for generating both personal and community resilience has been identified in earlier research (Maidment, Tudor, Campbell, \& Whittaker, 2015). Its application to a disaster environment however, had not been tested until the current research was conducted.

\section{Meaning making}

Within the context of a major natural disaster, it is not uncommon for individuals to question what appear to have been routines of life, the things taken for granted, and to wonder at one's own sense of purpose for facing the future. This existential examination takes place through making meaning of the disaster event itself and through reflection on the environmental, social and economic changes brought about as a result of the disaster. Engaging with meaning-making processes plays a critical role in recovery post-disaster (Park, 2016). Meaning-making refers to:

[T] he process of using signs, through which we as human beings build a meaningful relationship with the environment, with ourselves and with others through culture. More specifically, meanings are the continuously changing outcomes of this process. (Bendassolli, 2017, p. 604)

Using the activity of designing and making to come to terms with, and to shape meaning out of significant and often difficult life events has been identified in earlier research. The artefacts made became "symbols of life experiences" (Pöllänen, 2013, p. 221), where crafting was "seen as not only a way to analyse life situations but a tool for handling them" (p. 222). It is at this point that the connection between crafting and wellbeing becomes most evident.

\section{Wellbeing}

Many of the crafting endeavours that came to light in post-earthquake Canterbury were designed and made collectively or were created by individuals in a group setting. The capacity for both social connectedness and participation to be protective and curative factors for mental health is well researched (Saeri, Cruwys, Barlow, Stronge, \& Sibley, 2017) with notions of belonging and inclusion being integral to strengthening wellbeing. In a context where everyday life had become chaotic and simple tasks like doing the laundry or getting to work were problematic, drawing upon an established routine of attending a craft group provided a sense of routine where a network of relational safety and support could be found (Horghagen et al., 2014).

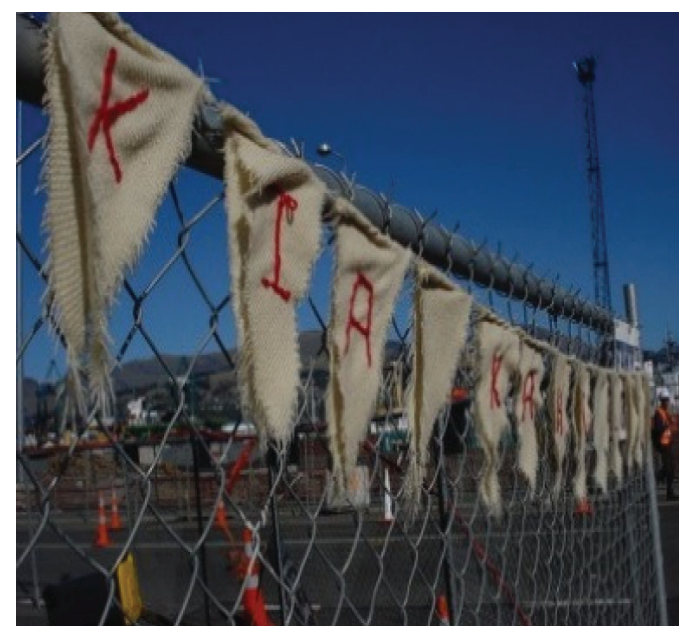

Bettina Evans. Kia kaha message. Ceismic Archive.

There is little focus within the literature about the role of craft in restoring a sense of place within disaster contexts. An earthquake, by its very nature, markedly changes the physical environment and disrupts the personal and social experiences of people living in the affected area. The crafting practices we discuss in this paper reflect the women's desires to, in some way, exercise agency over the environment, to beautify where there was rubble and steel but, in so doing, send a message of solidarity and commitment to those living in these particular places.

\section{Human geography's theorising of place}

Within the human geography literature, place is understood as an inseparable combination of objective and subjective 
dimensions constituted within the interactions between people and groups, institutionalised land uses, and the language of representation (Saar \& Palang, 2009). As geographical entities, places are bounded by physical parameters, as municipalities, suburbs, neighbourhoods, communities and homes (Gesler \& Kearns, 2002, p. 5). Also referred to as a locality, place provides the setting for social relations, including visible and concrete aspects such as parks, buildings and roads. Place is simultaneously a social construction referring to the meaning people attribute to specific spaces and themselves.

The notion of a sense of place, refers to the "attitudes, beliefs, meanings, and interpretations that people associate with a particular place" (Steele, 1981, as cited by Chamlee-Wright \& Storr, 2009, p. 617). Chamlee-Wright and Storr (2009) outline that sense of place incorporates three narrower concepts, those of place attachment, place identity, and place dependence. Place attachment concerns the emotional and cognitive bond that occurs between an individual and their environment. Place identity is the way in which the individual understands their own sense of self in relation to their physical environment "by means of a complex pattern of conscious and unconscious ideas, beliefs, preferences, feelings, values, goals and behavioural tendencies and skills [sic]" (Proshansky, 1978, as cited by Chamlee-Wright \& Storr, 2009, p. 617). Finally, place dependence refers to an individual's perceptions of the suitability of a specific place, in comparison to another place. It is important to attend to the plurality of place-making (Cresswell, 2014), given the earthquakes were a Canterbury-wide event which, whilst diverse in its effects, also provided a significant common experience for people. Their meanings of place were intertwined within individual and collective dimensions, based on personal biography and common experience.

We are interested how the processes and outcomes of women's crafting were able to facilitate a restorative sense of place in post-earthquake. Gesler (1992) introduced the concept of therapeutic landscape into the human geography literature. Essentially, therapeutic landscape refers to the physical, experiential and social characteristics of certain environments that are productive in providing a "healing sense of place" for its inhabitants. Through providing a sense of escape, a safe space for self-expression, and opportunities for solitary reflection, some settings enable what Moore et al. (2013, as cited by Bell, Foley, Houghton, Maddrell, \& Williams, 2018) describes as affective shifts for people. Individuals are able to transition from living with chaos and uncertainty to a sense of safety, comfort and belonging, to venturing outside oneself. Many of the women crafters we spoke with commented on their crafting providing experiences of respite, distraction and inclusion within the groups they attended.

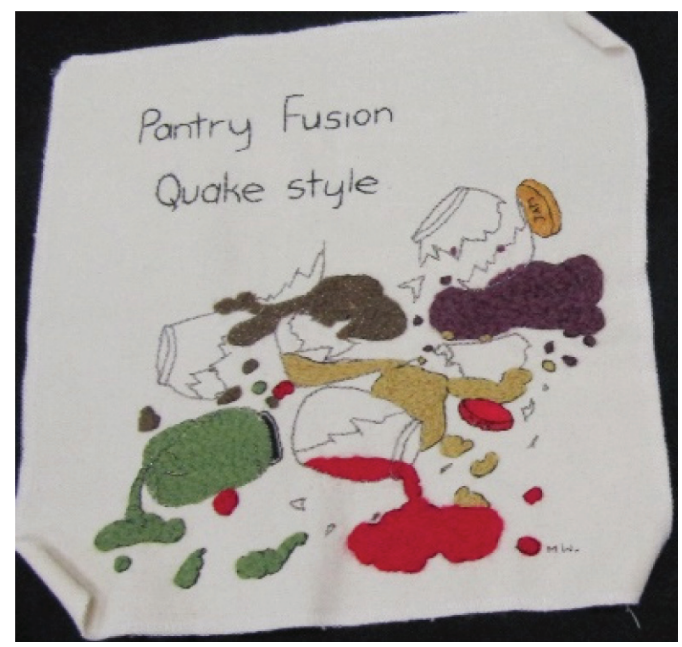

Authors' own. Embroidery of 'pantry fusion'.

The healing features of a place are recursive, such that settings and the sense people make from them arise within a series of interactions. One significant way in which this can occur is through symbolic communication, which refers to the way people interact with each other through symbolic systems such as written and oral language, pictures, mimics, gestures and actions (Mueller \& Schade, 2012, p. 84). Symbols such as crafted objects 
can provide a way of "feeling" a place. To achieve this, the people living in that environment need to be able to recognise the particular expression of a symbol. This means the association between expression and meaning of a symbol has to be learned before the symbol can be effectively used in communication in order to gain understanding (Mueller \& Schade, 2012, p. 84). Considering the symbolic role that craft plays in rendering settings within postearthquake Christchurch, therapeutic means attending to the affective meanings of the craft objects themselves.

Finally, examining women's craft activities calls into focus the gendered dimensions of therapeutic places. As Dyck (2005) comments, foregrounding gender highlights the hidden ways in which women contribute via their caring work to therapeutic place-making and how these localised care practices are embedded within wider relations of power. These caring practices are recognised as often a response to the gaps in social service support created by neoliberal policy (Dyck, 2005, p. 238). In a recent study Alston et al. (2018) make note of how, in the aftermath of the 2009 Black Saturday fires in Victoria, Australia, the women participants reported they had been drawn into the community focussed recovery processes, and had taken up roles to care for and nurture others. In the Christchurch context, where there were clear policy imperatives that prioritised community-led recovery actions and initiatives (Canterbury Earthquake Recovery Authority [CERA], 2014), it is relevant to examine the ways in which this devolved care was fulfilled by women and their crafting. Thus, exploring craft as a social practice and a form of symbolic communication connected with therapeutic place-making provides an important space to explore the role of women's caring work and its contribution to the social, cultural, economic and political processes of the earthquake recovery programme in Christchurch. We contend that craft is a relational, therapeutic and symbolic activity which promoted wellbeing and a stronger sense of place after the earthquakes.

\section{Method}

Ethics approval was sought and received from University of Canterbury Human Ethics Committee to conduct the field work for this research. We completed nine individual semistructured, 60-minute interviews alongside five focus group 90-minute interviews with a total of 35 participants ranging in age from 35-80 with two men being part of the participant population; the remaining 33 were women. The participants chose whether they wanted to participate in a focus group or individual interview. The recruitment for this research therefore included purposive sampling which sought to target people who had actively crafted during the aftermath of the earthquakes. The sample was derived from local new items and advertisements about craft gatherings that were happening in Christchurch and surrounding districts. Participants predominantly identified as New Zealand European. As such, the individuals and groups of people we met with were not ethnically diverse. This may have been because the recruitment strategy did not involve targeting specific population groups or distributing our research information sheet through services and organisations associated with ethnic specific groups. In fact, we did not try to access participants through services at all as, at the time of conducting the field work, most were still operating out of temporary premises and starting to grapple with significant insurance difficulties. Within this context we did not think a request for research participants via agencies and community organisations was appropriate, as Christchurch had become a mecca for disaster tourists and researchers with both NGO and statutory services being targeted by researchers.

The interview transcripts for this article were coded using applied thematic analysis (Guest, McQueen, \& Namey, 2012). The data were coded independently by two of the researchers with agreement reached on the identification of three themes. These themes included connection to place, the symbolism of craft, and the healing experience of craft group participation. To ensure confidentiality, all the 
identifying characteristics of participants have been removed from the following excerpts and the names used are pseudonyms.

A clear limitation of this research is that the findings illustrate views of a small sample and could not be generalised beyond the context of the post-earthquake Canterbury environment. A second limitation is the absence of gender and ethnic diversity in the research participants. During data collection we did not specifically ask questions about diversity, and we did not seek out a diverse participant group. Recruitment occurred by simply responding to advertisements about crafting that we located in the Canterbury news media. In terms of Men's crafting, future research could add to the literature on other community programmes such as the "Men's Shed", which has been positively linked with mental wellbeing (Morgan et al., 2007). However, in order to conduct research focussed on Māori crafting practices, a kaupapa Māori methodology would need to be undertaken (see Smith, 1999), which would mean ensuring the research is generated and undertaken by Māori.

\section{Findings}

The findings from the research demonstrate differing ways in which the significance of place was reflected in the craftwork. Participants interpreted the concept of place in descriptive, symbolic, and therapeutic ways.

\section{Crafting connection to place}

Crafting in the aftermath of the earthquake provided a physical space for community members to be together and to re-engage with their physical communities. A group of women crafters based in Lyttelton described how they set up camp on the footpath in their part of the city and crafted in the midst of the recovery efforts:

The dairy was open, that was the only thing...So here we are sitting there stitching, and there's soldiers and search and rescue people and the Navy all walking around us. (Francis)
The women recognised their desire to gather in their community place but not necessarily for the kinds of needs that the community welfare centres sought to address:

The only meeting place that there was, was set up as the Civil Defence, so if you had an issue you went there, but it wasn't a place that you would just sit and relax. (Melissa)

These kinds of alternative gathering places provided a means for the women to connect to people in their community and to their neighbourhood. As a practice of identity building, the women consciously sought to establish a new sense of themselves, each other and their altered physical environment.

There was also a sense that these public acts of crafting enabled other community members who passed by and observed the women's activities to re-connect to place and to each other. Some of these people expressed their appreciation of the women's public crafting through goods and kind:

... people gave us buttons and gave us materials, they gave us wool and I think other people also liked to be part of something positive, because there was very little positive at that particular stage about it, and just to be part of something, not to be alone - to be together, but also to be part of something that was positive. (Francis) (Tudor, Maidment, Campbell, \& Whittaker, 2015, p. 149)

Consistent with the notion of place attachment, crafting provided the women, and others not directly involved in making the objects, opportunities to interact with their local community places and to express a sense of positive connection.

\section{Symbolising place through craft}

Another feature of craft in the aftermath of the earthquake was the way in which the craft objects themselves were able to communicate shared meanings that helped people make sense of their new environment. Key to this was the dual communication process of the 


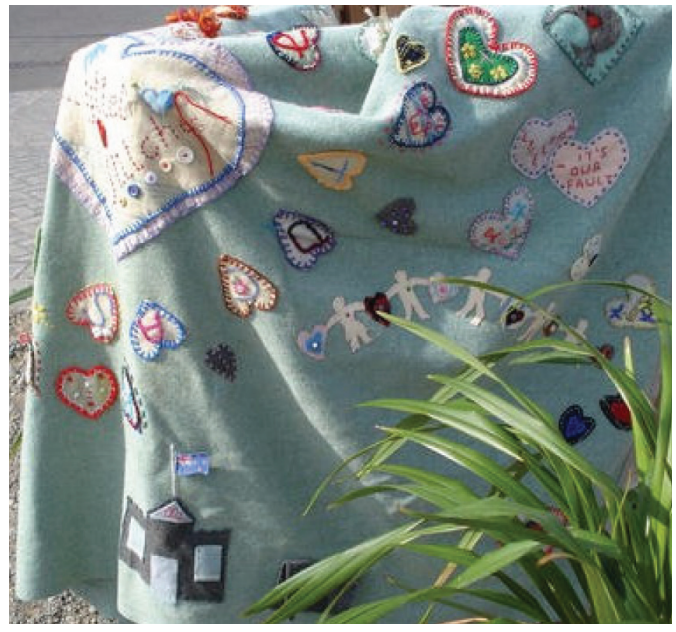

Bettina Evans. Embroidered blanket. Ceismic Archive.

women crafters reflecting on their feelings and thoughts associated with loss and grief and being able to recognise the shared quality of these experiences, as Lesley discusses:

I think it comes down to the feeling: the feeling of knowing what another person may be going through, and experiencing, because you're feeling those feelings yourself, and you can identify it with other people and you put it down on paper or in any other form of artwork. (Lesley)

Utilising craft to symbolise these shared experiences of place provided something more than just talking about the experiences would have provided:

... I found being able to define the experiences. We can talk about the shaking on the road and all these other things that happened and the house was falling to bits... But when you can isolate one event and put it into one scene, it defines the whole experience and brings it down to a touchable exercise. (Phylis)

For Phylis, the craft object (in this case a collection of embroidered images) provided a concrete symbol of the disruption of the earthquake. In a similar way, Lesley discusses the ability of crafted objects to make these kinds of fleeting but nonetheless significant experiences more tangible:
Like the Bayeux tapestry [the panel of embroidered scenes] it's never gonna go away, it'd always be there for others to see. And as much as they read somebody's account in the paper that can get thrown away, this particular idea will remain around for many years to come. And I just thought it would be a great way of showing what most people had to endure through that time of us having the earthquakes. (Lesley)

The crafters intentionally created objects that acted as representations of a whole range of personal and shared stories of the earthquake.

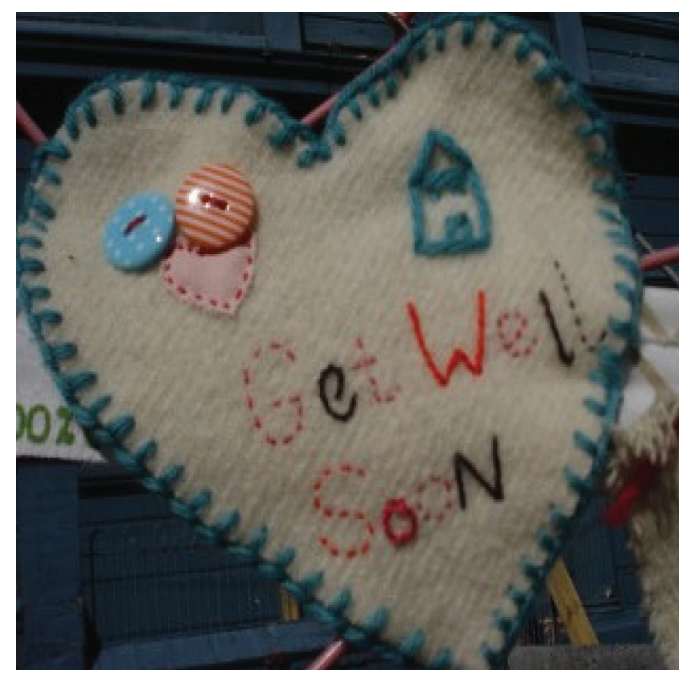

Bettina Evans. Embroidered heart. Ceismic Archive.

Some recurrent symbols created through craft were those of the buildings, houses and everyday facets of the physical environment broken and damaged by the earthquake, as Francis discusses:

I remember I stitched little houses because housing was such a big thing because my house was gone and lots of other people's houses were either broken or destroyed,... Before, we never talked about each other's houses, did we? You just lived in a house and that was it. Suddenly, a house became a symbol for so many things: being home, not being home, and about being broken and about going home and wanting to be home. (Francis) 
These craft objects reflect the acknowledgement of one of the main ways in which a major earthquake manifests itself, through the destruction of the physical environment. Crafting the lost physical buildings and dwellings provided a means to communicate and connect with the sense of security that participants once took for granted. Many of the places and objects represented by the craft objects no longer exist. The crafted objects not only symbolised what so many individuals and families had personally experienced but also provided a shared biography of loss for the city.

The symbolic objects that the women crafted also offered new and different representations of post- earthquake life. The craft objects communicated this restorative meaning in two main ways. Firstly, through the placement of these crafted objects in visible places. Nicole discusses how she and her fellow women crafters made crocheted squares that they attached to the temporary fences that served to block off unsafe buildings and areas of the city from the public:

That was something that was a giving back to Christchurch. It was making it look pretty and it was therapeutic and rewarding... (Nicole)

Judith discusses how the public displays of craft in the city enabled a more balanced view for people:

I think those artworks like that are important... So it helps with everything being pulled down and so much decimation and destruction to see something (positive)... (Judith)

Locating these craft objects in places where they could be seen gave the crafters a sense that they were able to beautify the environment.

Secondly, some of the craft objects reflected changes in the physical environment that gave reason for hope. Pat sought to represent in her embroidery that, over time, the initial

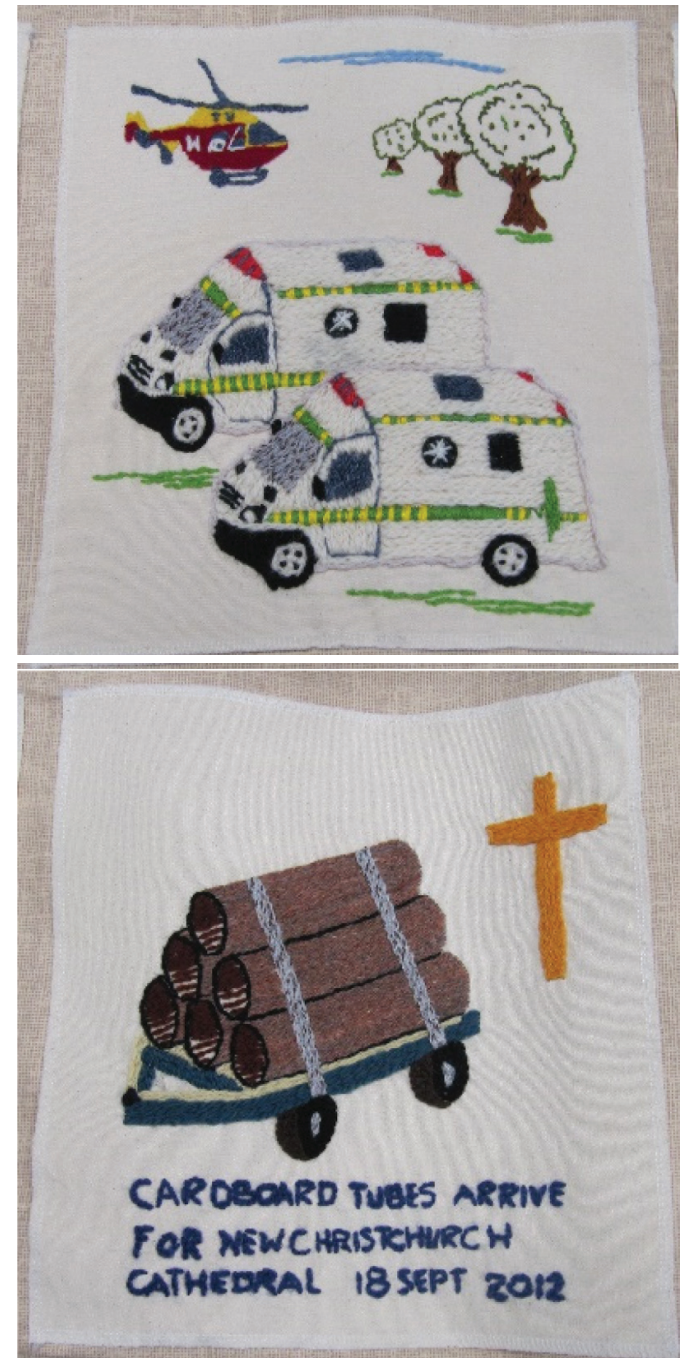

Authors' own. 'Dark and light' embroideries.

chaos and bleakness that immediately followed the earthquake had shifted:

I like the darker side with all the activity going on with the helicopters and all the ambulances and all this sort of thing, there was people injured, and all the rest of it. And the lighter side was like the cardboard tubing for the cathedral. It was starting to build up to something more lighter, there was hope...but it indicated that there was thinking on them terms, that there's hope now, something was coming through. (Pat)

Jean wished to document the positivity of a practice that many people took up in 
Christchurch, that of putting flowers in the road cones which had become a feature of the numerous road works sites in the city:

I chose to do the line of cones going off into the distance and the cone guard of honour, cos I thought that was a wonderful idea...that people could put the flowers in as something anyone could do...It wasn't any grand gesture - just something that you could do, and a symbol of hope... (Jean)

The women's craft works offered a range of alternative representations of place in Christchurch. Little sense would have been made of these visible representations of the built environment if the crafters did not recognise that these qualities had the capacity to act as symbols of collective experience (Mueller \& Schade, 2012).

\section{Craft groups as therapeutic places}

The women participants consistently described the craft groups as caring and supportive. There were numerous facets of the groups that seemed to account for the sense of wellbeing that crafting offered the women. Firstly, the craft groups were run in locations that were separate from the women crafters' homes as Rebecca discusses:

I found that coming to craft group was a normal thing whereas at home things were not normal. And to be with all the other ladies who were going through exactly the same as I was, and to be able to laugh and joke and just act normal. Then you would go home to no water, no toilet... (Rebecca)

The groups functioned as an escape from the disruptive and unsettled nature of the women's home lives in the aftermath of the earthquakes. They also provided routine and structure for the crafters, something that was lacking in the immediate aftermath of the earthquake. Secondly, the separation from the chaos and disruption was not just in terms of physical location, the groups offered the women reprieve from the emotional and cognitive effects of the earthquake. Claire describes how going to her craft group offered a break from thinking:

I come along here and I just relax when I get here. It's just nice. And there have been nights where I think I've come along and I haven't even bothered knitting; I've just sat and been an observer, cos sometimes the brain's too tired to actually function. (Claire)

Whereas Marjorie describes the healing that came from the humour and laughter in her group:

We laughed for so long...It was a release, it was an absolute release. And when I went away from this place, I felt as if I'd been on valium, I just felt so high, so good... (Marjorie)

Consistent with the literature on therapeutic landscapes, the craft groups provided an oasis from the chaos that followed the earthquake as well as opportunities for selfexpression (Moore et al., 2013, as cited by Bell et al., 2018) which, in a range of ways, facilitated affective shifts for many of the crafters. Through their participation in the craft groups, the women were provided with some time and space to reflect on the different effects and meanings they took from the earthquakes in a social context that was physically, cognitively and emotionally separate from their home-lives.

\section{Women's places}

The majority of the crafters who participated in this research were women. These gendered characteristics of the craft groups were described as a positive feature for many of the women we spoke to, as Joanne discusses:

And to come here and see the ladies sitting in there and the companionship that goes and you can go along and say, well "that's amazing, what an amazing 
job," and they go, "oh really?"...At first it was all, everyone was telling their stories about it, but it was just the support you had - it felt safe and okay to talk about it. (Joanne)

The comradery enabled experiences of inclusion and belonging for some of the women who had previously felt alone, as Catherine discusses:

Well after the quake I felt terribly isolated, terribly alone and I didn't know what other people were going through.

And then I got the message there was an afternoon tea here in the outside building. And to come and see faces I knew, that they had gone through roughly the same things that I was going through. (Catherine)

The openness and mutuality expressed by the women in her craft group enabled Catherine to experience a sense of inclusion and belonging. Through establishing sites of trust, safety and commonality, the craft groups enabled the women to provide care and support to each other. However, just as the gendered make-up of the groups was noted as an asset for some of the women, others, particularly those from one craft group that had a male participant, wondered if it was a barrier, as Francis describes:

I think maybe particularly for men, there is still this sort of thing that craft is particularly a women's thing, [laughter]...But the gender thing, certainly, I think could be an obstacle [for men]. (Francis)

In this instance, Francis considers the representation and make-up of craft groups as predominantly women's places as a barrier to men being able to participate in them.

\section{Discussion}

It is evident from the findings that the activity of crafting helped participants navigate the biographical disruption caused by the earthquake events. In particular, participants who crafted together talked about the healing possibilities crafting offered in terms of facilitating a therapeutic place where the women could unwind and just be with people who understood the extraordinary events they had all experienced. Those who participated in groups expressed how the process of coming together with others to make their works generated a strong sense of social and emotional connectedness.

The women who gathered together to craft met in a range of places including a community centre, a church lounge, a retail shop, participant homes and, in one instance, out on the street immediately after the earthquakes when all of Lyttelton's meeting spots were too damaged to use. The way the women who met in groups spoke about the impact of crafting together reflected a sense of relational safety, clearly resonating with the notion of inhabiting a therapeutic landscape (Moore et al., 2013, as cited by Bell et al., 2018). The women talked of recounting their earthquake stories while crafting, asking questions of others present and seeking solutions to practical problems. Group members acted as a sounding board affording opportunity to problem solve and deal with a diverse range of both practical and emotional needs. Crafting provided a medium for some people to connect with others in a range of ways, including donating materials to be used in crafting endeavours or simply attending a group without actually making anything. The significant therapeutic contribution offered by self-generated community groups such as the ones we met with remain unaccounted for and invisible in the disaster recovery literature yet clearly reflect the notion of communal coping identified in the disaster literature (Richardson \& Maninger, 2016).

Many of the craft works provided reference to a shared sense of place, that is, an understanding of the geographic and temporal context in which the crafting took place (Cresswell, 2014). The embroidered 
cone guard of honour, one piece of which was to become a collective work, represents the many thousands of road cones used in Christchurch and surrounding areas during extensive repairs of the roads, water and sewage systems. The cones each host a flower symbolic of the memorial action taken one and two years after the February 2011 earthquake where lives lost and disrupted were recognised with efforts to place a flower in every single cone. The Port Hills seen in the distance remind the viewer that, while much has changed, some landmarks remain steadfast. Examining the data through the lens of place serves to highlight the interface between peoples' meaning-making processes and the physical environment.

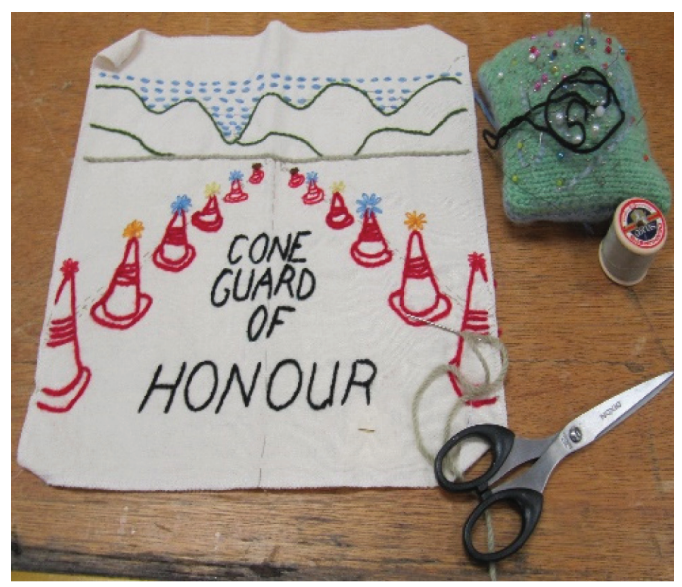

Authors' own. Cone of Honour embroidery.

Many of the women we spoke to did not consciously plan to use crafting to resolve feelings of loss, claim agency or care for others. Instead they intuitively knew their hand-made works would help heal and bring joy to both themselves and others in different ways. This tacit understanding which we explored as part of the interviews defies the "traditional understanding of research and its contribution to knowledge, which requires explicit evidence and justification to be perceived as 'rigorous'" (Niedderer \& Townsend, 2014, p. 633). We also found in participant responses hints for how social work practitioners might creatively use crafting to enhance interventions with different client groups.
The craft groups provided a low-cost, nonhierarchical forum for women to connect with others in ways that fostered strong, supportive social connections. As such, encouraging girls or women to learn or reconnect with crafting in a group setting can potentially address issues of social isolation and boredom. In line with earlier research, participants who worked alone also derived a sense of pleasure and achievement from crafting. These findings suggest that service users who do not, or cannot, move out of their own home environment might also benefit from engaging with some form of crafting activity. For some of the participants we spoke to crafting provided an outlet for emotional expression of loss as well as being used as a coping mechanism in times of significant stress. Many of the service users social workers come in contact with feel stressed, at odds with their life circumstances and in need of strengthened social ties.

Frequently people are living in poverty and have few resources to use in any form of leisure activity. Interest within crafting communities to contribute to sustainability, reuse materials, share resources and teach new skills, means that help can be readily at hand within community crafting groups for newcomers to learn and be supported in this endeavour.

When talking with service users as part of an assessment process, some discussion that takes account of place-based wellbeing and explores the place of artistry, craft, and creativity can help uncover latent hopes and aspirations. This is an often-overlooked area in contemporary social work practice with its focus on risk assessment and administrative compliance. Opening up possibilities to engage in creative activity can provide fulfilling and sustainable spaces for generating hope and achievement in service user lives.

For practitioners working within the postdisaster recovery space, this research has provided ample evidence of the distinctive benefits experienced by people from crafting in groups. Fostering opportunities for people to engage in these creative pursuits generates opportunities to access practical help and advice while providing relational and therapeutic 
safety for people to express difficult emotions and strengthen connections with others.

\section{Acknowledgement}

We wish to acknowledge the generosity of Bettina Evans, Lyttelton resident, for allowing us to use her photographs stored on the UC Ceismic (Canterbury earthquake digital archive) website, University of Canterbury.

\section{References}

Aiena, B. J., Buchanan, E. M., Smith, C. V., \& Schulenberg, S. E. (2016). Meaning, resilience, and traumatic stress after the Deepwater Horizon oil spill: A study of Mississippi coastal residents seeking mental health services. Journal of Clinical Psychology, 72(12), 1264-1278.

Beatley, T. (2014). Filling gaps. Planning, 80(1), 52-53.

Bell, S. L., Foley, R., Houghton, F., Maddrell, A., \& Williams, A. M. (2018). From therapeutic landscapes to healthy spaces, places and practices: A scoping review. Social Science \& Medicine, 196, 123-130.

Bendassolli, P. (2017). Emptiness and work: A meaning making perspective. Integrative Psychological and Behavioral Science, 51(4), 598-617.

Canterbury Earthquake Recovery Authority (CERA). (2014). Community in mind: Background document. Retrieved from https://www.cph.co.nz/wp-content/.../ communityinmindbackgrounddocument.pdf

Chamlee-Wright, E., \& Storr, V. H. (2009). "There's no place like New Orleans": Sense of place and community recovery in the Ninth Ward after Hurricane Katrina. Journal of Urban Affairs, 31(5), 615-634.

Collier, A. D., Wayment, H. A., \& Birkett, M. (2016). Impact of making textile handcrafts on mood enhancement and inflammatory immune changes. Art Therapy, 33(4), 178-185.

Cour, K., Josephsson, J., \& Luborsky, M. (2005). Creating connections to life during life-threatening illness: Creative activity experienced by elderly people and occupational therapists. Scandinavian Journal of Occupational Therapy, 28, 104-112.

Cresswell, T. (2014). Place: An introduction. London, UK: John Wiley \& Sons.

Denovan, A., \& Macaskill, A. (2017). Stress resilience and leisure coping among university students: applying broad-and-build theory. Leisure Studies, 36(6), 852-865.

Dyck, I. (2005). Feminist geography, the "everyday", and local-global relations: Hidden spaces of placemaking. Canadian Geographer/Le Géographe canadien, 49(3), 233-243.

Earthquake Commission. (2014). Make it count. Retrieved from http://www.eqc.govt.nz/make-it-count

Evans, B. (n.d.). Ceismic. Canterbury earthquake digital archive. University of Canterbury. Retrieved from http:// www.ceismic.org.nz/

Enarson, E. (2006). Women and girls last? Averting the second post-Katrina disaster. Social Science Research
Council. Retrieved from http://understandingkatrina. ssrc. org/Enarson, 1-18.

Enarson, E., \& Morrow, B. H. (1998). The gendered terrain of disaster. New York, NY: Praeget.

Fariello, A. (2011). Making and naming: The lexicon of studio craft. In M. Buszek (Ed.), Extra/ordinary: Craft and contemporary art (pp. 23-42). Durham, NC: Duke University Press.

Gesler, W. M. (1992). The cultural geography of health care. Pittsburgh, PA: University of Pittsburgh Press.

Gesler, W. M., \& Kearns, R. A. (2002). Culture/place/health. London, UK: Routledge.

Gordon, L. (2013). Preserving family and community: Women's voices from the Christchurch earthquakes. Disaster Prevention and Management, 22(5), 415-424.

Guest, G., McQueen, K., \& Namey, E. (2012). Applied thematic analysis. Thousand Oaks, CA: Sage Publications.

Heijmans, A. (2001). Vulnerability: A matter of perception. London, UK: Benfield Greig Hazard Research Centre.

Horghagen, S., Fostvedt, B., \& Alsaker, S. (2014). Craft activities in groups at meeting places: supporting mental health users' everyday occupations. Scandinavian Journal of Occupational Therapy, 21(2), 145-152.

Kai Tiaki Nursing New Zealand. (2018). Canterbury children to receive better mental health care. Kai Tiaki Nursing New Zealand, 24(2), 8. Retrieved from https://www.nzno. org.nz/resources/library/online_journals

Kohut, M. (2011). Making art from memories: Honouring deceased loved ones through a scrapbooking bereavement group. Art Therapy, 28(3), 123-131.

Macpherson, H., Hart, A., Heaver, B. (2016). Building resilience through group visual arts activities: Findings from a scoping study with young people who experience mental health complexities and/or learning difficulties, Journal of Social Work, 16(5), 541-560.

Maidment, J., \& Macfarlane, S. (2011). Older women and craft: Extending educational horizons in considering wellbeing. Social Work Education, 30(6), 700-711.

Maidment, J., Tudor, R., Campbell, A., \& Whittaker, K. (2015). Use of domestic craft for meaning-making post-disaster. Kōtuitui: New Zealand Journal of Social Sciences Online, 10(2), 144-152.

Morgan M., Hayes R., Williamson M., \& Ford C. (2007). Men's Sheds: A community approach to promoting mental health and well-being, International Journal of Mental Health Promotion, 93, 48-52.

Mueller, A., \& Schade, M. (2012). Symbols and place identity: A semiotic approach to internal place branding - case study Bremen (Germany). Journal of Place Management and Development, 5(1), 81-92.

Niedderer, K., \& Townsend, K. (2014). Designing craft research: Joining emotion and knowledge. The Design Journal, 17(4), 624-647.

Park, C. (2016). Meaning making in the context of disasters. Journal of Clinical Psychology, 72(12), 257-301.

Pöllänen, S. (2013). The meaning of craft: Craft makers' descriptions of craft as an occupation. Scandinavian Journal of Occupational Therapy, 20(3), 217-227.

Pöllänen, S. (2015). Crafts as leisure-based coping: Craft makers' descriptions of their stress reducing activity. Occupational Therapy in Mental Health, 31(2), 83-100. 


\section{ORIGINAL ARTICLE}

Richardson, B., \& Maninger, L. (2016). "We were all in the same boat": An exploratory study of communal coping in disaster recovery. Southern Communication Journal, 81(2), 107-122. doi:10.1080/1041794X.2015.1111407

Riley, J., Corkhill, B., \& Morris, C. (2013). The benefits of knitting from personal and social wellbeing in adulthood: Findings from an international study. British Journal of Occupational Therapy, 76(2), 50-57.

Saar, M., \& Palang, H. (2009). The dimensions of place meanings. Living Reviews in Landscape Research, 3(3), 5-24.

Saeri, A., Cruwys, T., Barlow, F., Stronge,S., \& Sibley, C (2018). Social connectedness improves public mental health: Investigating bidirectional relationships in New Zealand attitudes and values survey. Australian \& New Zealand Journal of Psychiatry, 52(4), 365-374.

Schofield-Tomschin, S., \& Littrell, M. (2001). Textile handcraft guild participation: A conduit to successful aging Clothing and Textile Research Journal, 19(2), 41-51.

Smith, L. T. (1999). Decolonizing methodologies: Research and indigenous peoples. New Zealand: Zed Books.

Spittlehouse, J. K., Joyce, P. R., Vierck, E., Schluter, P. J., \& Pearson, J. F. (2014). Ongoing adverse mental health impact of the earthquake sequence in Christchurch, New Zealand. Australian \& New Zealand Journal of Psychiatry, 48(8), 756-763.

Tudor, R., Maidment, J., Campbell, A., \& Whittaker, K. (2015). Examining the role of craft in post-earthquake recovery: Implications for social work practice. British Journal of Social Work, 45(suppl_1), i205-i220. 